\title{
A fuzzy compromise programming approach for the Black-Litterman portfolio selection model
}

\author{
Mohsen Gharakhani and Seyed Jafar Sadjadi*
}

Department of Industrial Engineering, Iran University of Science \& Technology, Tehran, Iran

\begin{tabular}{|c|c|}
\hline C H R O N I C L E & A B S T R A C T \\
\hline $\begin{array}{l}\text { Article history: } \\
\text { Received October 2, } 2012 \\
\text { Accepted December } 3,2012 \\
\text { Available online } \\
\text { December } 32012 \\
\text { Keywords: } \\
\text { MCDM } \\
\text { Fuzzy MCDM } \\
\text { COPRAS-F } \\
\text { Portfolio optimization } \\
\text { Black-Litterman optimization } \\
\text { Markowitz optimization } \\
\text { Fuzzy compromise programming }\end{array}$ & $\begin{array}{l}\text { In this paper, we examine advanced optimization approach for portfolio problem introduced by } \\
\text { Black and Litterman to consider the shortcomings of Markowitz standard Mean-Variance } \\
\text { optimization. Black and Litterman propose a new approach to estimate asset return. They } \\
\text { present a way to incorporate the investor's views into asset pricing process. Since the investor's } \\
\text { view about future asset return is always subjective and imprecise, we can represent it by using } \\
\text { fuzzy numbers and the resulting model is multi-objective linear programming. Therefore, the } \\
\text { proposed model is analyzed through fuzzy compromise programming approach using } \\
\text { appropriate membership function. For this purpose, we introduce the fuzzy ideal solution } \\
\text { concept based on investor preference and indifference relationships using canonical } \\
\text { representation of proposed fuzzy numbers by means of their corresponding } \alpha \text {-cuts. A real world } \\
\text { numerical example is presented in which MSCI (Morgan Stanley Capital International Index) is } \\
\text { chosen as the target index. The results are reported for a portfolio consisting of the six national } \\
\text { indices. The performance of the proposed models is compared using several financial criteria. }\end{array}$ \\
\hline
\end{tabular}

(C) 2013 Growing Science Ltd. All rights reserved.

\section{Introduction}

Modern portfolio theory (MPT) first introduced by Markowitz (1952) in his seminal paper, has changed the investment world, substantially. This theory tries to maximize portfolio expected return subject to a given amount of portfolio risk, or equivalently at the same time, minimizes risk while keeping a given level of expected return. The theory has been widely used in practice, in the investment industry and the history witnessed several Nobel Laureates for the theory. In recent years, however, the MPT has been widely criticized because of its high sensitivity to estimated parameters.

The Black-Litterman model was first published in an international Goldman Sachs Fixed Income document in 1990 and made two major contributions to the asset allocation problem (Black \& Litterman, 1990). First, it provides an intuitive prior based on the capital asset pricing model (CAPM) equilibrium market portfolio, as a starting point in the estimation of asset returns. Second, it provides a straight forward way to consider investor view and combines it with prior information. In addition,

* Corresponding author.

E-mail addresses: sjsadjadi@iust.ac.ir (S. J. Sadjadi)

C 2013 Growing Science Ltd. All rights reserved. doi: $10.5267 /$ j.ds1.2012.12.001 
these views can be partial or complete and can span arbitrary and overlapping sets of assets. It estimates expected excess returns and covariances, which requires input parameters to the optimization problem. These two contributions result in a modified expected return vector, which improves the initial expected returns and can be applied in portfolio optimization. In this paper, we formulate the portfolio selection problem as multi-objective linear program. There are two important criteria in any investment decision, which are risk and return. We make use of Black-Litterman approach to formulate portfolio return. In order to keep linearity of the model we can measure portfolio risk through its beta that is a common risk measure in the literature. We apply fuzzy multiobjective programming in order to cope with the proposed model.

The rest of the paper is organized as follows: In section 2, we survey the recent approaches in the investment literature. Section 3 discusses the Black-Litterman approach in details, which yields an appropriate estimate of asset returns. Thereafter, we formulate mathematically the advanced portfolio selection problem considering investor's views as fuzzy variables in section 4 . In section 5 , we present a real-world numerical example to illustrate the presented procedure. Finally, section 6 is devoted to the concluding remarks.

\section{Literature review}

In the recent intricate and dynamic world, investment decision is a demanding human cognitive process with regard to uncertainties such as price and interest volatility. Therefore, both institutional investors and practitioners are always occupied with managing their portfolios, not only to optimize returns, but also to minimize total potential risks. Traditionally, asset allocation was based on the expected mean-variance analysis. It relies on the premise where investors would diversify assets to maximize expected return and minimize risk. Consider a market with $n$ risky assets where $\mu$ denotes the vector of the expected asset returns and $\Sigma$ is covariance matrix. The classical portfolio optimization problem can be described as:

$$
\begin{aligned}
& \min (1-\lambda) \sqrt{x^{t} \sum x}-\lambda x^{t} \mu \\
& x^{t} \mathbf{1}=1 \\
& x \geq 0
\end{aligned}
$$

where the portfolio $x$ is given in terms of relative investments into the risky assets, i.e. it holds that $x^{t} \mathbf{1}=1$. Naturally, the feasibility set $x$ can contain additional constraints such as short sale prohibition $x \geq 0$. The parameter $\lambda$ is defined as the investor risk aversion measure, which is used for tracing the whole efficient frontier. The dependability of MPT, as well as other mathematical models in determining the optimal portfolio depends heavily on availability of valid market data, sometimes they might not be able to reflect real-world situations accurately (Olaleye, 2008; Falkenbach, 2009). Thus, these market data do not represent one's decision as some information is not quantifiable in nature, i.e. the human cognitive process.

Specialist judgment seems to offer an acceptable alternative to handle this challenging problem. By relaxing the crispness of rigorous modeling and enabling a robust representation of expert knowledge, fuzzy logic systems can guide decision makers. The foundation of fuzzy logic for representing imprecise, vague and ambiguous information was first proposed by Zadeh (1965). They used fuzzy logic in expressing vague information into a scientific approach and later enhanced it via the introduction of the concept of linguistic variable. His approach has been further developed and widely used in investment, engineering design and decision-making, along with artificial intelligence and urban planning. According to Ko and Cheng (2003), fuzzy logic not only provides an approximate but also it is effective descriptions for ill-defined, or troublesome to cope with existing complex systems. The fuzzy approach can capture uncertainty in a realistic way (French, 2001). In order to overwhelm these problems, expert's knowledge is incorporated in modeling. Expert judgments are 
pervasive and important to any analytical system (Fischhoff, 2002). It could be used in modifying the expected return and variance in accordance with various factors, which might not be taken into account by mathematical computations, for instance, the MPT. Keeney and Von Winterfeldt (2002) explained that human linguistic qualification is preferable to a simple numerical expression of knowledge since it can well reflect expert's vagueness. It is therefore necessary to integrate such qualification into model computations. The application of fuzzy theory in decision making in different real world issues has been well documented in different contexts (Perng et al., 2005, Bagnoli \& Smith, 1998, Pagourtzi et al., 2003). Watada (1997) introduced the vague goals of expected return and risk in order to consider fuzzy portfolio selection problem. Leon et al. (2002) proposed a fuzzy approach describing soft constraints and amended infeasibility in portfolio optimization problem. In Tanaka et el. (2000), the authors applied the possibility theory to cope with uncertainty and solve the portfolio optimization problem. According to Lai et al. (2002), Wang and Zhu (2002), and Giove et al. (2006) linear interval programming model has been used for portfolio selection. Carlsson et al. (2002) introduced a possibilistic approach for selecting portfolios with the highest utility value assuming assets returns as trapezoidal fuzzy numbers.

Wang et al. ( 2005) and Zhang et al. (2005) discussed the general weighted possibilistic portfolio problem. Lacagnina and Pecorella (2006) developed a multistage stochastic soft constraint fuzzy program with recourse to handle both uncertainty and imprecision as well as providing a portfolio management problem. Lin et al. (2005) proposed a systematic approach by incorporating fuzzy theory in conjunction with portfolio matrix in order to help managers in arriving a better understanding of the overall competitive aspects of their business portfolios. Huang (2006) provided two portfolio selection models with fuzzy returns by chance criteria represented though credibility measure. Huang (2007) proposed two models for portfolio selection problem where the security returns are stochastic variables with fuzzy information. Fei (2007) studied the optimal consumption and portfolio choice with ambiguity and anticipation. Bilbao-Terol et al. (2006) applied fuzzy compromise programming to portfolio selection problem. Ammar (2008) solved the fuzzy portfolio optimization problem as a convex quadratic programming.

Zhang et al. (2007) presented two types of portfolio selection models based on lower and upper possibilistic means and variances, respectively, and introduced the notions of lower and upper possibilistic efficient portfolio. Li et al. (2010) stated that portfolio returns are generally asymmetric, and investors would prefer a portfolio return with larger degree of asymmetry when the mean value and variance are the same. In order to measure the asymmetry of fuzzy portfolio return, they defined the concept of skewness is as the third central moment. In the above mentioned works, there are two fundamental criteria including expected return and risk which an ordinary investor usually considers. Arenas Parra et al. (2001) proposed a model that considers three criteria viz., return, risk and liquidity. Ehrgott et al. (2004) took into consideration five criteria including short and long term return, dividend, ranking and risk; then use multi criteria decision making (MCDM) approach to solve the resulting optimization problem. Fang et al. (2006) proposed a portfolio rebalancing model with transaction costs using fuzzy decision theory considering three criteria. Black and Litterman (1990) add uncertainty on the views by means of Bayesian formulas.

There are too many researchers focusing on the classical Markowitz optimization in fuzzy context. However, there is a little attention to the advanced portfolio optimization proposed by Black and Litterman. To the best of our knowledge, Lawrence et al. (2009) was the only researcher who addressed this problem and proposed fuzzy goal programming to solve advanced portfolio problem assuming input data viz. mean portfolio return and beta, as fuzzy numbers. This paper aims to shed light on incorporating investor knowledge by fuzzy set theory into the advanced asset allocation model. We assume mean asset return and covariance as fixed estimated parameters and consider 
fuzzy views. In order to extend the Black-Litterman approach in fuzzy context we will explain the most important features in section 3 .

\section{Black-Litterman approach}

Black and litterman (1990) proposed a novel methodology (BL in sequel) that combines the market model with the investor's views. Using Bayes' formula, they calculate the posterior distribution, which can be applied instead of simple market expected returns. Consider a market of $N$ securities with random return $X$ which is normally distributed as $X \sim \mathrm{N}(\mu, \Sigma)$. Usually the covariance matrix $\Sigma$ can be estimated with the exponential smoothing of the past returns (Engle \& Managanelli, 2004). Black and Litterman (1990) further modeled $\mu$ as a normal random variable such that $\mu \sim \mathrm{N}(\pi, \tau \Sigma)$, where $\pi$ is the best available estimate for $\mu$ and $\tau$ represent the uncertainty of this estimate. It should be noted that the higher degree of confidence to the market results in the lower the parameter $\tau$, and vice versa. This reference model is normal and centered around the CAPM equilibrium. On the other words, BL adopt CAPM equilibrium distribution as the prior distribution. CAPM can simply model estimated mean excess returns (Sharpe, 1964). The model assumes there is a linear relationship between risk as measured by standard deviation and return. In addition, it imposes return to be normally distributed.

Black and Litterman (1990) proposed that $\pi$ can be estimated as $\pi=2 \bar{\lambda} \Sigma \widetilde{w}$ in which $\widetilde{w}$ represents the equilibrium portfolio, which stems from the average risk aversion level $\bar{\lambda}$. On the other hand, BL supposes that the investor has her own views that can be defined as "A statement on the market that can potentially clash with reference market model". For example, a situation where the investor strongly believes that first asset outperform the second is shown as $x_{1}-x_{2} \geq 0$. BL considers views only on expectations in normal market. They focus on linear views that include $K$ views represented by $K \times N$ dimensional array called pick matrix in which $K^{\text {th }}$ row specify the weight of the corresponding view. For more information on pick matrix the interested readers referred to Black and Litterman (1990). They proposed a normal model for views as $P_{\mu} \sim \mathrm{N}(\nu, \Omega)$ in which $P_{\mu}$ is a vector denoting investor views, $v$ and $\Omega$ represent views and uncertainty thereof respectively. Meucci (2009) proposed that the uncertainty about investor's views inherits its structure from the market volatilities and correlations, so $\Omega$ can be determined as $\frac{1}{c} P \Sigma P$, where parameter $c$ represents the overall level of confidence in views. Using Bayes formula, BL calculate the conditional distribution of $\mu$ and call it posterior distribution. The results are as follows,

$\mu \mid v, \Omega \sim N\left(\mu^{B L}, \Sigma^{B L}\right)$,

where

$\mu^{B L}=\pi+\tau \Sigma P^{\prime}\left(\tau P \Sigma P^{\prime}+\Omega\right)^{-1}(v-P \pi)$,

$\Sigma^{B L}=\left((\tau \Sigma)^{-1}+P^{\prime} \Omega^{-1} P\right)^{-1}$.

Readers interested in the proof are referred to Meucci (2009). This normal posterior distribution represents the corresponding modification of reference model i.e. Markowitz Mean-Variance optimization because of introduction of the investor's views. With this posterior distribution, we can now solve the mean-variance optimization to get $\mu$.

\section{Proposed fuzzy Black-Litterman}

In the traditional BL approach (1990) the investor view is a key factor that is assumed to be a known and crisp vector. In this paper, we consider the investor view as fuzzy numbers, which can efficiently handle verbal statement of the experts. We estimate portfolio return via fuzzified BL formula, which should be maximized. Furthermore, we calculate the portfolio risk through its total beta, which 
usually should be minimized. Thus, the resulting linear programming problem has two conflicting objective that has to be compromised based on investor point of view, which is summarized as follows,

$\max \tilde{z}=\tilde{\mu}^{\prime} x$

$\min w=\beta^{\prime} x$

subject to

$x^{\prime} \mathbf{1}=1$,

$x \geq 0$,

where the fuzzy return vector $\tilde{\mu}$ is as follows,

$\tilde{\mu}=\tilde{\mu}^{B L}=\pi+\tau \Sigma P^{\prime}\left(\tau P \Sigma P^{\prime}+\Omega\right)^{-1}(\tilde{v}-P \pi)$

Since trapezoidal fuzzy number is a more general form rather than triangular fuzzy number, in this paper, we propose trapezoidal fuzzy numbers to represent investor views. A simple trapezoidal fuzzy number could be represented with a quadruple as $\tilde{v}_{i}=\left(v_{i}^{1}, v_{i}^{2}, v_{i}^{3}, v_{i}^{4}\right)$ as illustrated in fig 1 , where $v_{i}^{\alpha}$ is the membership function and $v_{i}^{1}, \ldots, v_{i}^{4}$ are parameters bounding the fuzzy numbers. In the trapezoidal fuzzy number with this form, the membership function between $v_{i}^{2}$ and $v_{i}^{3}$ is equal to 1 and for values lower than $v_{i}^{1}$ or higher than $v_{i}^{4}$ the membership function is equal to zero. For other values between $\left(v_{i}^{1}, v_{i}^{2}\right)$ or $\left(v_{i}^{3}, v_{i}^{4}\right)$, the membership function is some value between 0 and 1 .

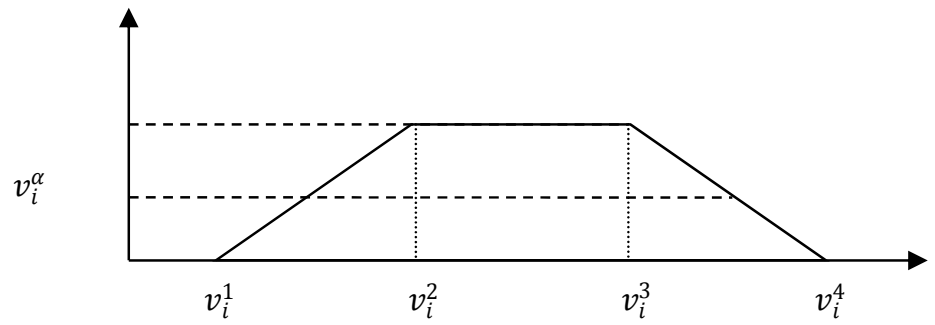

Fig. 1. Trapezoidal fuzzy number

In order to cope with the resulting multi-objective linear programming problem we use Lee and Li (1993) approach. They proposed a coherent way to handle fuzzy multi-objective linear programming with fuzzy parameters. Consider a fuzzy multi-objective linear programming problem of form:

$\max \tilde{Z}(x)=\left(\tilde{c}_{1} x, \tilde{c}_{2} x, \ldots, \tilde{c}_{l} x\right)$,

$\min \widetilde{W}(x)=\left(\tilde{c}^{\prime}{ }_{1} x, \tilde{c}^{\prime}{ }_{2} x, \ldots, \tilde{c}^{\prime}{ }_{r} x\right)$,

subject to

$x \in X=\left\{x \in \mathbb{R}^{n} \mid \tilde{A} x * \tilde{b}, x \geq 0\right\}$,

where $\tilde{c}_{k},{\widetilde{c^{\prime}}}_{s}$ are n-dimensional vectors representing objective confidents of maximization and minimization problems, respectively, $\tilde{b}$ is an m-dimensional vector, $\tilde{A}$ is an $m \times n$ matrix, and the all components are fuzzy numbers. The asterisk shows that it could be either $\leq$ or $\geq$ constraints. Let $(x)_{\beta}^{\alpha}$ be a solution of problem (5) where $\alpha \in[0,1]$ states "the grade of possibility" which means a grade at which all fuzzy coefficients are feasible, and $\beta \in[0,1]$ denotes "the level of compromise to which the solution satisfies all of the fuzzy goals" while the coefficients are at a feasible level $\alpha$. By means of Bellman -Zadeh (1970) rule of conjunction, the fuzzy parameters $\alpha$ can be expressed as

$\alpha=\min _{k, s, i, j}\left\{\mu_{\tilde{c}_{k j}}, \mu_{\widetilde{c}_{s j}}, \mu_{\tilde{a}_{i j}}, \mu_{\tilde{b}_{i}} \mid k=1, \ldots, l, s=1, \ldots, r, i=1, \ldots, m, j=1, \ldots, n\right\}$

Eq. (6) means that the feasibility of the whole system is equal to the possibility of the most impossible component in the system or equivalently the minimum possible component. On the other words, the higher the possibility of the coefficient is, the stronger the limitations on the coefficient 
are. Obviously, the optimal solution for a given level of $\alpha$ is reached when the E.Q. 6 holds for all subscript:

$\mu_{\tilde{c}_{k j}}=\mu_{\tilde{c}_{\prime} s j}=\mu_{\tilde{a}_{i j}}=\mu_{\tilde{b}_{i}}=\alpha$

Let $\widetilde{P}_{\alpha}$, be the $\alpha$-cut of a fuzzy number $\widetilde{P}_{\alpha}^{U}$ and $\tilde{P}_{\alpha}^{L}$ are respectively the upper and lower bound of its $\alpha$-cut:

$\tilde{P}_{\alpha}^{L} \leq \tilde{P}_{\alpha} \leq \tilde{P}_{\alpha}^{U}$.

Finally, the multi-objective linear program (5) could be reformulated as bellows (Lee \& Lim, 1993):

$\left(\tilde{Z}_{k}\right)_{\alpha}^{U}=\sum_{j=1}^{n}\left(\tilde{c}_{k j}\right)_{\alpha}^{U} \cdot x_{j}, k=1, \ldots, l$,
$\left(\widetilde{W}_{s}\right)_{\alpha}^{L}=\sum_{j=1}^{n}\left(\tilde{c}_{s j}^{\prime}\right)_{\alpha}^{L} \cdot x_{j}, s=1, \ldots, r$.

In Eq. (9) $k$ and $s$ are enumerating indices related to maximization and minimization problems, respectively. In addition, when defined asterisk operator $*$ in the constraint is $\leq$ and $\geq$ the corresponding constraint can be reformulated as Eq. (10) and Eq. (11), respectively.

$\sum_{j=1}^{n}\left(\tilde{a}_{k j}\right)_{\alpha}^{L} \cdot x_{j} \leq\left(\tilde{b}_{i}\right)_{\alpha}^{U}, \forall i=1, \ldots, m$
$\sum_{j=1}^{n}\left(\tilde{a}_{k j}\right)_{\alpha}^{U} \cdot x_{j} \geq\left(\tilde{b}_{i}\right)_{\alpha}^{L}, \forall i=1, \ldots, m$

It is obvious that for a given level of $\alpha$ the problem becomes a deterministic linear problem solved with single objective function (Lee \& $\mathrm{Li}, 1993$ ). Let define four types of objective functions in order to become able to compromise different objective of the problem. Ideal and anti-ideal solution could be defined similar to Lee and Li (1993), which denote the best and worst cases, respectively. The assume that $\left(\tilde{Z}_{k}\right)_{\alpha}^{+},\left(\widetilde{W}_{s}\right)_{\alpha}^{+}$and $\left(\tilde{Z}_{k}\right)_{\alpha}^{-},\left(\widetilde{W}_{s}\right)_{\alpha}^{-}$are the ideal and anti-ideal solutions, respectively, which can be achieved through solving each of the following single objective linear programming problem independently for all possible values of $k$ and $s$ :

$$
\begin{aligned}
& \max _{x \in X_{\alpha}}\left(\tilde{Z}_{k}\right)_{\alpha}^{+}=\sum_{j=1}^{n}\left(\tilde{c}_{k j}\right)_{\alpha}^{U} \cdot x_{j} \\
& \min _{x \in X_{\alpha}}\left(\widetilde{W}_{s}\right)_{\alpha}^{+}=\sum_{j=1}^{n}\left(\tilde{c}_{k j}^{\prime}\right)_{\alpha}^{L} \cdot x_{j} \\
& \max _{x \in X_{\alpha}}\left(\widetilde{W}_{s}\right)_{\alpha}^{-}=\sum_{j=1}^{n}\left(\tilde{c}_{k j}^{\prime}\right)_{\alpha}^{U} \cdot x_{j} \\
& \min _{x \in X_{\alpha}}\left(\tilde{Z}_{k}\right)_{\alpha}^{-}=\sum_{j=1}^{n}\left(\tilde{c}_{k j}\right)_{\alpha}^{L} \cdot x_{j}
\end{aligned}
$$

In order to obtain the optimum compromising level for each degree of $\alpha$ we have to solve the following single objective linear programming problem:

$\max \beta$

subject to

$\beta \leq \mu_{k}^{\alpha}\left(\tilde{Z}_{k}\right)$

$\beta \leq \mu_{s}^{\alpha}\left(\widetilde{W}_{s}\right)$, 
$\beta \in[0,1]$,

$x \in X_{\alpha}$,

where $\mu_{k}^{\alpha}\left(\tilde{Z}_{k}\right)$ and $\mu_{s}^{\alpha}\left(\widetilde{W}_{s}\right)$ are the level of realization of different objective functions that can be defined as follows:

$\mu_{k}^{\alpha}\left(\tilde{Z}_{k}\right)=\frac{\left[\sum_{j=1}^{n}\left(\tilde{c}_{k j}\right)_{\alpha}^{U} \cdot x_{j}-\left(\tilde{Z}_{k}\right)_{\alpha}^{-}\right]}{\left[\left(\tilde{Z}_{k}\right)_{\alpha}^{+}-\left(\tilde{Z}_{k}\right)_{\alpha}^{-}\right]}$

$\mu_{s}^{\alpha}\left(\widetilde{W}_{s}\right)=\frac{\left[\left(\widetilde{W}_{s}\right)_{\alpha}^{-}-\sum_{j=1}^{n}\left(\tilde{c}_{k j}^{\prime}\right)_{\alpha}^{L} \cdot x_{j}\right]}{\left[\left(\widetilde{W}_{s}\right)_{\alpha}^{-}-\left(\widetilde{W}_{s}\right)_{\alpha}^{+}\right]}$

Now, let $\lambda$ be the level of overall satisfaction to the solution $(x)_{\beta}^{\alpha}$ based on fuzzy goals and coefficients. According to Bellman-Zadeh's rule $\lambda$ is calculated as $\lambda=\min \{\alpha, \beta\}$, where $\alpha, \beta$ are two unknown parameters. The $\alpha$ parameter shows the level of possibility of the fuzzy coefficients and the $\beta$ parameter denotes the compromise degree between different objective functions. A very efficient scheme to solve this problem (5) numerically assuming trapezoidal fuzzy number is described as the following algorithm,

Step 1. Define $\varepsilon=$ accuracy of tolerance set $\alpha=0$.

Step 2. Set solve the problem 13 to obtain $\beta$ and $x$.

Step 3. If $|\alpha-\beta| \leq \varepsilon$ then let $\lambda=\min \{\alpha, \beta\}$ and $x^{*}=x$ and go to step 4. Otherwise set $=\frac{\alpha+\beta}{2}$.

Step 4. Output $\lambda$ and $x^{*}$.

For any given value of $\alpha$, after obtaining $\left(\tilde{Z}_{k}\right)_{\alpha}^{+},\left(\widetilde{W}_{s}\right)_{\alpha}^{+},\left(\tilde{Z}_{k}\right)_{\alpha}^{-}$and $\left(\widetilde{W}_{s}\right)_{\alpha}^{-}$, one should solve the following linear programming problem in order to achieve the compromise level $\beta$,

$\max \beta=\frac{1}{l+r}\left(\sum_{k=1}^{l} \beta_{k}+\sum_{s=1}^{r} \beta_{s}\right)$

subject to

$\beta \leq \beta_{k}$,

$\beta \leq \beta_{S}$

$\beta, \beta_{k}, \beta_{s} \in[0,1]$,

$x \in X_{\alpha}^{\prime}$,

where $\beta_{k}$ and $\beta_{s}$ can be defined as follows,

$\beta_{k}=\frac{\left[\sum_{j=1}^{n}\left(c_{k j}^{(4)}-\left(c_{k j}^{(4)}-c_{k j}^{(3)}\right) \alpha\right) \cdot x_{j}-\left(\tilde{Z}_{k}\right)_{\alpha}^{-}\right]}{\left[\left(\tilde{Z}_{k}\right)_{\alpha}^{+}-\left(\tilde{Z}_{k}\right)_{\alpha}^{-}\right]}, \quad r=1, \ldots, l$,

$\beta_{s}=\frac{\left[\left(\widetilde{W}_{s}\right)_{\alpha}^{-}-\sum_{j=1}^{n}\left(c_{k j}^{(1)}-\left(c_{k j}^{(2)}-c_{k j}^{(1)}\right) \alpha\right) \cdot x_{j}\right]}{\left[\left(\widetilde{W}_{s}\right)_{\alpha}^{-}-\left(\widetilde{W}_{s}\right)_{\alpha}^{+}\right]}, \quad s=1, \ldots, r$.

In this paper, we have two objective functions including return and risk where one of which is fuzzy and we have a single non-fuzzy constraint that makes our problem even simpler than general cases. The return objective function uses fuzzified BL approach while the risk objective uses portfolio beta. Since the portfolio beta is calculated based on historical data, and it is not based on investor views, we do not fuzzify it. We should solve the following multi-objective fuzzy linear programming in which the investor's views are assumed to be fuzzy. 
$\max (\tilde{\mathrm{z}})_{\alpha}^{\mathrm{U}}=\sum_{\mathrm{j}=1}^{\mathrm{n}}\left(\tilde{\mu}_{\mathrm{j}}\right)_{\alpha}^{\mathrm{U}} \mathrm{x}_{\mathrm{j}}$

$\min w=\sum_{j=1}^{n} \beta_{j} x_{j}$

subject to

$\sum_{j=1}^{n} x_{j}=1$

$\mathrm{x} \geq 0$.

\section{Numerical example}

In this section, we apply a real data set in order to compare the performance of the results, empirically. MSCI index is used as the target index, which measures the performance of equity market within developed countries maintained by Morgan Stanley Capital International incorporation since 1969. MSCI world index contains 24 developed country market indices, which is a common benchmark for global equity funds. It should be noted that emerging markets index has been excluded from the benchmark. We used six industrial countries market index: United States (USA), Germany $(D)$, France $(F)$, United Kingdom $(U K)$, Switzerland $(C H)$ and Japan $(J A P)$.

\section{Table 1}

Risk/return characteristics of MSCI total return indices in terms of US\$; All figures in \%

\begin{tabular}{cccccccccc}
\hline \multirow{2}{*}{ Index } & \multicolumn{2}{c}{$\begin{array}{c}\text { Whole observation period: Jan } \\
\text { 2003 to April 2011 }\end{array}$} & \multicolumn{3}{c}{$\begin{array}{c}\text { In-the-sample period: Jan 2003 to } \\
\text { August 2009 }\end{array}$} & $\begin{array}{c}\text { Out-of-the-sample period: Sep 2009 } \\
\text { to April 2011 }\end{array}$ \\
\hline & $M$ & $\Sigma$ & $B$ & $\mu$ & $\Sigma$ & $b$ & $\mu$ & $\Sigma$ & 6 \\
\hline $\mathrm{MSCl}$ & 0.44 & 4.79 & 1.00 & 0.27 & 4.81 & 1.00 & 1.12 & 4.76 & 1.00 \\
USA & 0.36 & 4.41 & 0.90 & 0.10 & 4.37 & 0.89 & 1.38 & 4.51 & 0.92 \\
JAP & 0.27 & 5.00 & 0.77 & 0.33 & 5.20 & 0.82 & -0.01 & 4.20 & 0.59 \\
UK & 0.31 & 5.31 & 1.04 & 0.14 & 5.28 & 1.03 & 1.01 & 5.48 & 1.09 \\
D & 0.77 & 7.11 & 1.39 & 0.63 & 7.21 & 1.40 & 1.31 & 6.87 & 1.35 \\
$F$ & 0.46 & 6.51 & 1.29 & 0.42 & 6.22 & 1.24 & 0.60 & 7.75 & 1.52 \\
CH & 0.71 & 4.82 & 0.87 & 0.59 & 4.84 & 0.89 & 1.15 & 4.82 & 0.78 \\
\hline
\end{tabular}

Monthly Average return and Standard deviation are in \%

beta is respect to MSCI

Monthly data are collected from January 2003 to April 2011; including 100 monthly return observations. Moreover, the whole observation period is decomposed into two sub-periods; from January 2003 to August 2009 including 80 observations used as in-the-sample observations, and from September 2009 to April 2011 including 80 observations assumed as out-of-the sample observations, which is used as the test set. In-the-sample period data are used for constructing optimized portfolios for the proposed models. On the other hands, the out-of-the-sample observations are applied to test the efficiency of obtained portfolio weights. Mean, standard deviation and beta relative to the MSCI world index of each series of data are summarized in Table 1. Consider an investor who is going to construct a portfolio using six country indices. The investor also has two views over the market as below:

$$
P=\left[\begin{array}{cccccc}
1 & 0 & 0 & 0 & 0 & 0 \\
0 & 0 & -1+1 & 0 & 0
\end{array}\right]
$$

which implies that the USA index will grow in the future and the German index outperform that of English. Counting on these views the result of implementing fuzzy multi-objective programming in fuzzy BL and non-fuzzy BL are summarized in Tables 2 and Table 3, respectively. It could be observed that the optimum point is for $\alpha=0.7$ which is presented in bold face. Fig. 2 depicts the efficient frontier for fuzzy and non-fuzzy BL models; which implies the fuzzified model has higher return for any given level of risk. 
Table 2

Results for fuzzy problem

\begin{tabular}{cccccccccccccc}
\hline$\alpha$ & $\mathrm{Z}^{+}$ & $\mathrm{Z}^{-}$ & $\mathrm{W}^{+}$ & $\mathrm{W}^{-}$ & $\beta$ & $\mathrm{Z}^{*}$ & $\mathrm{~W}^{*}$ & $\mu_{1}^{\mathrm{BL}}$ & $\mu_{2}^{\mathrm{BL}}$ & $\mu_{3}^{\mathrm{BL}}$ & $\mu_{4}^{\mathrm{BL}}$ & $\mu_{5}^{\mathrm{BL}}$ & $\mu_{6}^{\mathrm{BL}}$ \\
\hline 1 & 0.2186 & 0.1005 & 0.7 & 1.1 & 0.6866 & 0.1816 & 0.8253 & 0.1094 & 0.1752 & 0.1619 & 0.1106 & 0.2107 & 0.2186 \\
0.72 & 0.2245 & 0.098 & 0.7 & 1.1 & 0.7017 & 0.1868 & 0.8193 & 0.112 & 0.1797 & 0.166 & 0.1136 & 0.2199 & 0.2245 \\
0.715 & 0.2246 & 0.0979 & 0.7 & 1.1 & 0.702 & 0.1869 & 0.8192 & 0.112 & 0.1798 & 0.1661 & 0.1137 & 0.2201 & 0.2246 \\
0.71 & 0.2247 & 0.0979 & 0.7 & 1.1 & 0.7022 & 0.1869 & 0.8191 & 0.1121 & 0.1799 & 0.1662 & 0.1138 & 0.2203 & 0.2247 \\
0.705 & 0.2248 & 0.0978 & 0.7 & 1.1 & 0.7025 & 0.187 & 0.819 & 0.1121 & 0.18 & 0.1662 & 0.1138 & 0.2204 & 0.2248 \\
\hline $\mathbf{0 . 7}$ & $\mathbf{0 . 2 2 4 9}$ & $\mathbf{0 . 0 9 7 8}$ & $\mathbf{0 . 7}$ & $\mathbf{1 . 1}$ & $\mathbf{0 . 7 0 2 7}$ & $\mathbf{0 . 1 8 7 1}$ & $\mathbf{0 . 8 1 8 9}$ & $\mathbf{0 . 1 1 2 2}$ & $\mathbf{0 . 1 8}$ & $\mathbf{0 . 1 6 6 3}$ & $\mathbf{0 . 1 1 3 9}$ & $\mathbf{0 . 2 2 0 6}$ & $\mathbf{0 . 2 2 4 9}$ \\
\hline 0.695 & 0.225 & 0.0977 & 0.7 & 1.1 & 0.703 & 0.1872 & 0.8188 & 0.1122 & 0.1801 & 0.1664 & 0.1139 & 0.2208 & 0.225 \\
0.69 & 0.2251 & 0.0977 & 0.7 & 1.1 & 0.7032 & 0.1873 & 0.8187 & 0.1122 & 0.1802 & 0.1664 & 0.114 & 0.2209 & 0.2251 \\
0.685 & 0.2252 & 0.0976 & 0.7 & 1.1 & 0.7034 & 0.1874 & 0.8186 & 0.1123 & 0.1803 & 0.1665 & 0.114 & 0.2211 & 0.2252 \\
0.68 & 0.2254 & 0.0976 & 0.7 & 1.1 & 0.7037 & 0.1875 & 0.8185 & 0.1123 & 0.1804 & 0.1666 & 0.1141 & 0.2213 & 0.2254 \\
0.005 & 0.2435 & 0.0905 & 0.7 & 1.1 & 0.7203 & 0.2007 & 0.8119 & 0.1186 & 0.1913 & 0.1766 & 0.1214 & 0.2435 & 0.2395 \\
\hline
\end{tabular}

Table 3

Results for non-fuzzy problem

\begin{tabular}{cccccccccccccc}
\hline$\alpha$ & $\mathrm{Z}^{+}$ & $\mathrm{Z}^{-}$ & $\mathrm{W}^{+}$ & $\mathrm{Z}^{-}$ & $\beta$ & $\mathrm{Z}^{*}$ & $\mathrm{~W}^{*}$ & $\mu_{1}^{\mathrm{BL}}$ & $\mu_{2}^{\mathrm{BL}}$ & $\mu_{3}^{\mathrm{BL}}$ & $\mu_{4}^{\mathrm{BL}}$ & $\mu_{5}^{\mathrm{BL}}$ & $\mu_{6}^{\mathrm{BL}}$ \\
\hline All $\boldsymbol{\alpha}$ & 0.2092 & 0.105 & 0.7 & 1.1 & 0.6669 & 0.1744 & 0.8332 & 0.105 & 0.167 & 0.1549 & 0.1059 & 0.1973 & 0.2092 \\
\hline
\end{tabular}

Table 4 contains the weights of optimized portfolio of each method. Needless to say, the sum of each row equals one, which is a typical constraint in any asset allocation; and all weights are positive values which implies that short selling is prohibited. One could observe that the investor, which has a view like pick matrix $p$, will invest more in USA index than those who have not. Furthermore, such an investor does not invest in UK stock market anymore.

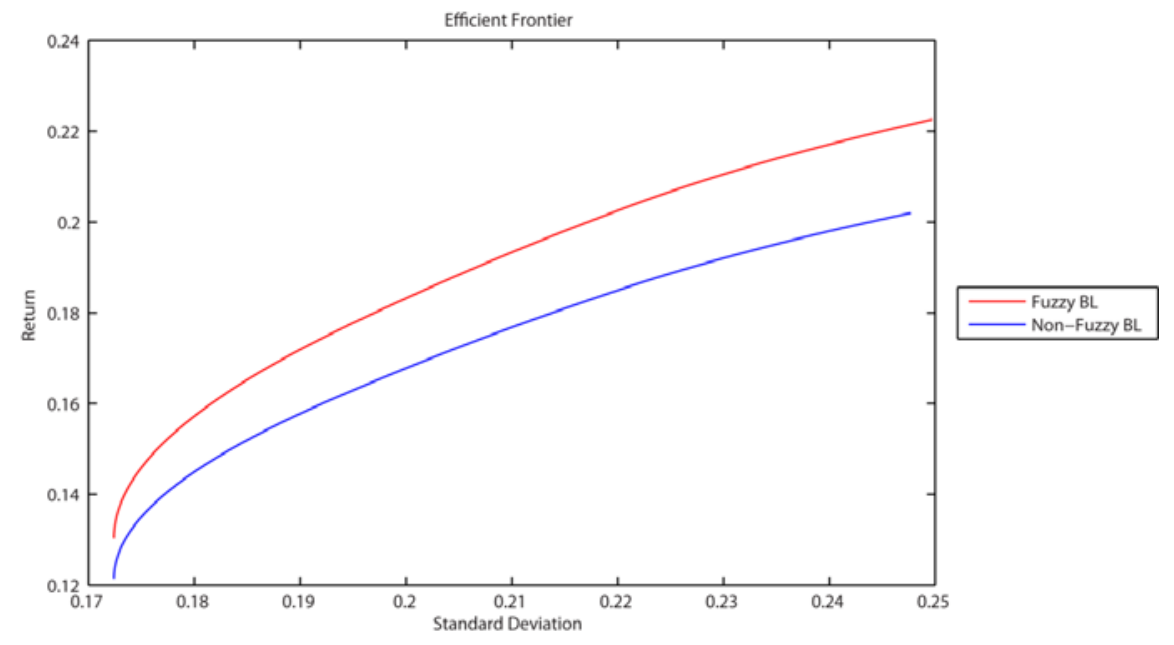

Fig. 2. Efficient frontier considering fuzzy and non-fuzzy BL model

Table 4

Optimized portfolio weights based on the in-the-sample period (Jan 2003 to August 2009) referring to different optimization models in \%

\begin{tabular}{lcccccc}
\hline Model & USA & $J A P$ & $U K$ & $D$ & $F$ & $C H$ \\
\hline Markowitz & 21.0 & 6.0 & 14.0 & 38.0 & 12.0 & 9.0 \\
Fuzzy BL & 54.0 & 0.0 & 0.0 & 43.0 & 1.5 & 1.5 \\
Non-fuzzy BL & 44.0 & 4.0 & 3.0 & 35.0 & 2.0 & 12.0 \\
\hline
\end{tabular}


Table 5 summarizes the comparison of different models using several financial criteria. Fig. 3 presents a graphical comparison of different models based on financial criteria. It could be observed from this graph that Fuzzy-BL model outperforms the others almost in all financial criteria. Since in all performance measures presented here the more is the better, one could conclude that the higher the resulting area the stronger the performance of corresponding portfolio. It should be noted that portfolio models in general and the BL model in particular are tools. These tools have both advantages and disadvantages. Estimating input data to the BL model is difficult. Therefore, it is of great importance that the investor using the model understands the implemented estimations and their inherent problems. On the other hand, Portfolio models are used in a social and organizational context. This context is of great importance for the use of the model.

Table 5

Risk/return characteristics of optimized portfolios, all figures in \%, Observation period: Feb 2009 to Aug 2011

\begin{tabular}{lcccccccc}
\hline Model & $\mathrm{R}(\mathrm{p})^{\mathrm{a}}$ & $\mathrm{STD} \mathrm{p})^{\mathrm{a}}$ & $\mathrm{TR}(\mathrm{p})^{\mathrm{b}}$ & Beta $^{\mathrm{c}}$ & $\begin{array}{c}\text { Information } \\
\text { ratio }^{\mathrm{d}}\end{array}$ & $\begin{array}{c}\text { Sharpe } \\
\text { ratio }^{\mathrm{e}}\end{array}$ & $\begin{array}{c}\text { Treynor } \\
\text { ratio }^{\mathrm{f}}\end{array}$ & $\begin{array}{c}\text { Market } \\
\text { ratio }^{\mathrm{g}}\end{array}$ \\
\hline Markowitz & 1.3 & 5.6 & 1.4 & 1.1475 & 3.62 & 0.89 & 0.04 & 1.0005 \\
Fuzzy BL & 1.5 & 5.4 & 1.1 & 1.1133 & 24.19 & 4.84 & 0.23 & 1.0026 \\
Non-fuzzy BL & 1.4 & 5.1 & 0.8 & 1.0587 & 19.89 & 3.23 & 0.16 & 1.0016 \\
MSCI World & 1.2 & 4.8 & - & 1.0000 & - & - & - & - \\
\hline
\end{tabular}

${ }^{\mathrm{a}}$ Monthly returns and standard deviations in $\%$

${ }^{\mathrm{b}}$ Tracking error measured by standard deviation of portfolio excess returnwith respect to MSCI $(\sigma(\mathrm{XB}-\mathrm{y}))$

${ }^{\mathrm{c}}$ Beta of each portfolio to MSCI world stock market index $\beta=\operatorname{cov}\left(R_{i}, R_{b}\right) / \operatorname{var}\left(R_{i}\right)$

${ }^{\mathrm{d}}$ Excess return to square root of tracking error in $\%$

${ }^{\mathrm{e}}$ Excess return to volatility ratio in $\%$

${ }^{\mathrm{f}}$ Excess return to beta in \%

${ }^{\mathrm{g}}$ Relative performance of tracking portfolio to benchmark index

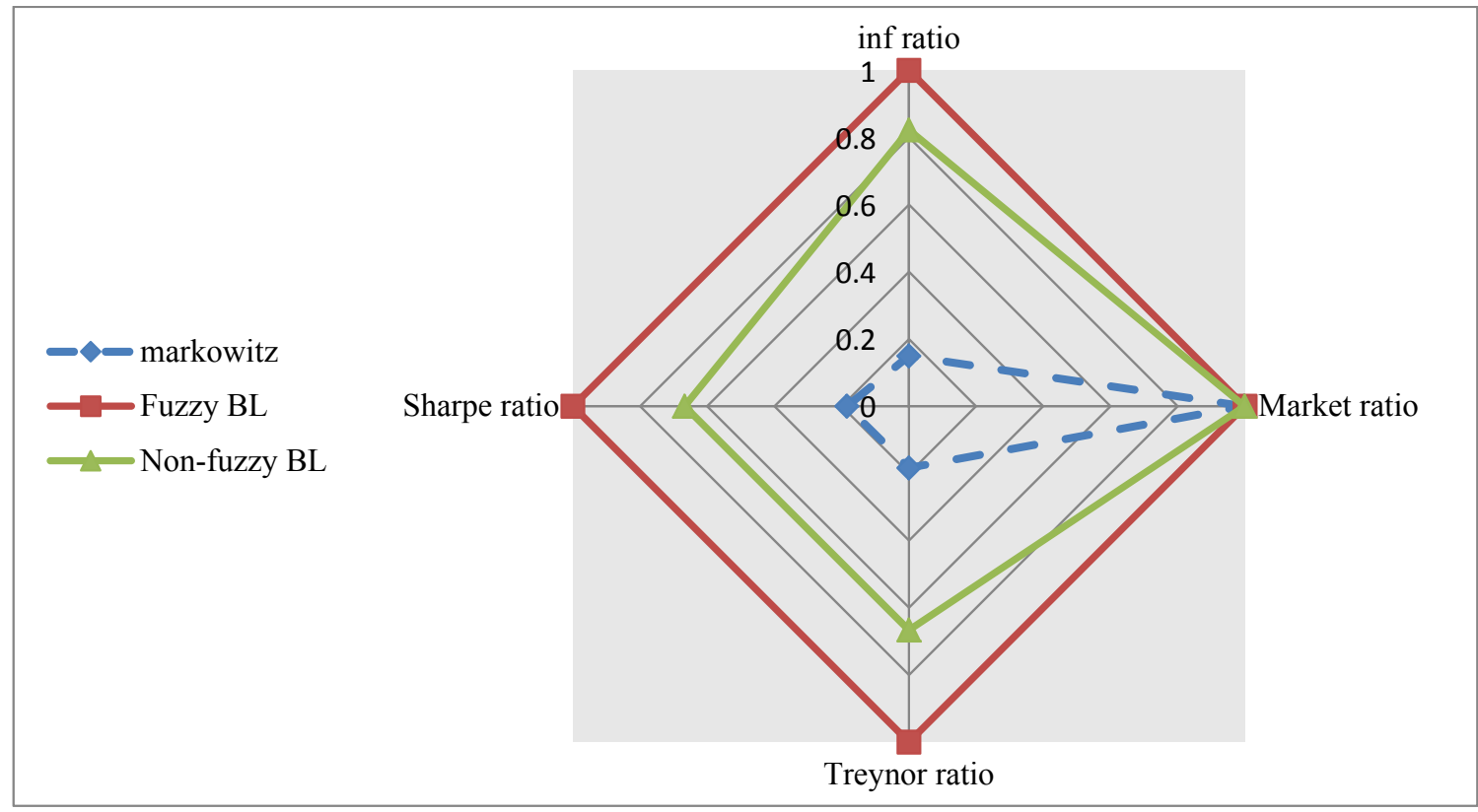

Fig. 3. Comparing different approaches based on financial criteria

\section{Concluding remarks}

In this paper, we have considered fuzzy portfolio selection problems based on Black-Litterman (BL) model, which is a useful tool of the investment in order for taking into account the investor's views into asset pricing process. Since the investor's view about future asset return is always subjective and 
imprecise, we have modeled it using fuzzy numbers and, obviously, the resulting model is multiobjective linear programming. The proposed model has been analyzed through fuzzy compromise programming approach using appropriate membership function. A real world numerical example has been presented in, which results are reported for a portfolio consisting of the six most important national indices including embracing Japan, USA, UK, Germany, Switzerland, and France. The performance of the proposed models is compared using several financial criteria. We have demonstrated that the proposed model could be solved analytically and efficiently by performing fuzzy multiple objective algorithm.

In the future, we will apply this fuzzy portfolio selection problem and solution methods to other asset allocation problems considering planning horizon and portfolio insurance. Nonetheless, this new proposed model of portfolio selection problems and the efficient solution methods will allow us to solve more complicate problems in real world situations under more random and ambiguous conditions.

\section{References}

Ammar, E. (2008). On solutions of fuzzy random multiobjective quadratic programming with applications in portfolio problem. Information Sciences 178, 468-484.

Arenas Parra, M., Bilbao Terol, A., \& Rodriguez Uria, M. (2001). A fuzzy goal programming approach to portfolio selection. European Journal of Operational Research, 133, 287-297.

Bagnoli, C., \& Smith, H. C. (1998). The theory of fuzz logic and its application to real estate valuation. Journal of Real Estate Research, 16, 169-200.

Bellman, R. E., \& Zadeh, L. A. (1970). Decision-making in a fuzzy environment, Management science, 17.

Bilbao-Terol, A., Pérez-Gladish, B., Arenas-Parra, M., \& Rodríguez-Uría, M. V. (2006). Fuzzy compromise programming for portfolio selection. Applied Mathematics and Computation, 173, 251-264.

Black, F., \& Litterman, R. B. (1990). Asset Allocation: Combining Investors Views with Market Equilibrium, Fixed Income Research.

Carlsson, C., Fullér, R., \& Majlender, P. (2002). A possibilistic approach to selecting portfolios with highest utility score, Fuzzy sets and systems, 131, 13-21.

Ehrgott, M., Klamroth, K., \& Schwehm, C. (2004). An MCDM approach to portfolio optimization. European Journal of Operational Research, 155, 752-770.

Engle, R. F., \& Manganelli, S. (2004). CAViaR: Conditional Autoregressive Value at Risk by Regression Quantiles. Journal of Business \& Economic Statistics, 22, 367-382.

Falkenbach, H. (2009). Diversification benefits in the Finnish commercial property market. International Journal of Strategic Property Management, 13, 23-35.

Fang, Y., Lai, K. K., \& Wang, S. Y. (2006). Portfolio rebalancing model with transaction costs based on fuzzy decision theory. European Journal of Operational Research, 175, 879-893.

Fei, W. (2007). Optimal consumption and portfolio choice with ambiguity and anticipation. Information Sciences, 177, 5178-5190.

Fischhoff, B. (2002). Eliciting knowledge for analytical representation, Systems, Man and Cybernetics, IEEE Transactions, 19, 448-461.

French, N. (2001). Decision theory and real estate investment: an analysis of the decision-making processes of real estate investment fund managers. Managerial and Decision Economics, 22, 399-410.

Giove, S., Funari, S., and Nardelli, C. (2006). An interval portfolio selection problem based on regret function. European Journal of Operational Research, 170, 253-264.

Huang, X. (2006). Fuzzy chance-constrained portfolio selection. Applied Mathematics and Computation, 177, 500-507. 
Huang, X. (2007). Two new models for portfolio selection with stochastic returns taking fuzzy information. European Journal of Operational Research, 180, 396-405.

Keeney, R. L., \& Von Winterfeldt, D. (2002). On the uses of expert judgment on complex technical problems. Engineering Management, IEEE Transactions, 36, 83-86.

Ko, C. H., \& Cheng, M. Y. (2003). Hybrid use of AI techniques in developing construction management tools. Automation in Construction, 12, 271-281.

Lacagnina, V., \& Pecorella, A. (2006). A stochastic soft constraints fuzzy model for a portfolio selection problem. Fuzzy sets and systems, 157, 1317-1327.

Lai, K., Wang, S., Xu, J., Zhu, S., \& Fang, Y. (2002). A class of linear interval programming problems and its application to portfolio selection. Fuzzy Systems, IEEE Transactions, 10, 698704.

Lawrence, K. D., Pai, D. R., Klimberg, R. K., \& Lawrence, S. M. (2009). A fuzzy programming approach to financial portfolio model. Financial Modeling Applications and Data Envelopment Applications, 53.

León, T., Liern, V., \& Vercher, E. (2002). Viability of infeasible portfolio selection problems: A fuzzy approach. European Journal of Operational Research, 139, 178-189.

Li, X., Qin, Z., \& Kar, S. (2010). Mean-variance-skewness model for portfolio selection with fuzzy returns. European Journal of Operational Research, 202, 239-247.

Lin, C., Tan, B., \& Hsieh, P. J. (2005). Application of the fuzzy weighted average in strategic portfolio management. Decision Sciences, 36, 489-511.

Markowitz, H. M. (1952). Portfolio Selection. Journal of Finance, 7, 77-91.

Meucci, A. (2009). Enhancing the Black-Litterman and related approaches: Views and stress-test on risk factors. Journal of Asset Management, 10, 89-96.

Olaleye, A. (2008). Property market nature and the choice of property portfolio diversification strategies: The Nigeria experience. International Journal of Strategic Property Management, 12, 35-51.

Pagourtzi, E., Assimakopoulos, V., Hatzichristos, T., \& French, N. (2003). Real estate appraisal: a review of valuation methods. Journal of Property Investment \& Finance, 21, 383-401.

Perng, Y. H., Hsueh, S. L., \& Yan, M. (2005). Evaluation of housing construction strategies in China using fuzzy-logic system. International Journal of Strategic Property Management, 9, 215-232.

Sharpe, W. F. (1964). Capital asset prices: A theory of market equilibrium under conditions of risk. Journal of Finance, 19, 425-442.

Stanley Lee E., Li, R. (1993). Fuzzy multiple objective programming and compromise programming with Pareto optimum. Fuzzy sets and systems, 53, 275-288.

Tanaka, H., \& Guo, P. (1999). Portfolio selection based on upper and lower exponential possibility distributions. European Journal of Operational Research, 114, 115-126.

Tanaka, H., Guo, P., \& Türksen, I. B. (2000). Portfolio selection based on fuzzy probabilities and possibility distributions. Fuzzy sets and systems, 111, 387-397.

Wang, S., \& Zhu, S. (2002). On fuzzy portfolio selection problems. Fuzzy Optimization and Decision Making, 1, 361-377.

Wang, X., Xu, W., Zhang, W., \& Hu, M. (2005). Weighted possibilistic variance of fuzzy number and its application in portfolio theory. Fuzzy Systems and Knowledge Discovery, 148-155.

Watada, J. (1997). Fuzzy portfolio selection and its applications to decision making. Fuzzy structures: current trends, 219.

Zadeh, L. A. (1965). Fuzzy sets. Information and control, 8, 338-353.

Zhang, W. G., \&Wang, Y. L. (2005). Portfolio selection: Possibilistic mean-variance model and possibilistic efficient frontier. Algorithmic Applications in Management, 203-213.

Zhang, W. G., Wang, Y. L., Chen, Z. P., \& Nie, Z. K. (2007). Possibilistic mean-variance models and efficient frontiers for portfolio selection problem. Information Sciences, 177, 2787-2801. 